Check for updates

Cite this: Phys. Chem. Chem. Phys. 2021, 23, 24789

Received 22nd July 2021,

Accepted 13th October 2021

DOI: $10.1039 / \mathrm{d} 1 \mathrm{cp} 03341 \mathrm{~g}$

rsc.li/pccp

\title{
Study of a phosphorescent cationic iridium(III) complex displaying a blue-shift in crystals $\uparrow$
}

\author{
Emiliano Martínez-Vollbert, (D) a Christian Philouze, ${ }^{a}$ Isabelle Gautier-Luneau, ${ }^{b}$ \\ Yohann Moreau, (D) ${ }^{c}$ Pierre-Henri Lanoë (D) *a and Frédérique Loiseau*a
}

\begin{abstract}
We report the synthesis and the characterization of a new cationic iridium(III) complex featuring two 1-( $p$-methoxyphenyl)-5-methoxybenzimidazole cyclometallating ligands and a dimethylbipyridine ancillary ligand. The complex has been fully characterized by $1 \mathrm{D}$ and $2 \mathrm{D} N \mathrm{NMR}\left({ }^{1} \mathrm{H},{ }^{13} \mathrm{C},{ }^{19} \mathrm{~F}\right.$ and $\left.{ }^{31} \mathrm{P}\right)$, elemental analysis and high-resolution mass spectrometry (HRMS). The photoluminescence studies performed in a solution, on amorphous powder and on crystals revealed an unexpected behavior. Indeed, the emission spectra observed in both solution $\left(\mathrm{CH}_{2} \mathrm{Cl}_{2}\right)$ and amorphous powder samples are centered at around $580 \mathrm{~nm}$, whereas in crystals the emission displays a large hypsochromic shift of $\sim 800 \mathrm{~cm}^{-1}\left(\lambda_{\mathrm{em}}=558 \mathrm{~nm}\right)$. X-ray diffraction experiments, photophysical studies and DFT calculations allow for rationalizing the hypsochromic shift.
\end{abstract}

\section{Introduction}

Phosphorescent iridium(III) complexes have attracted intensive research since the beginning of the 21st century for a large number of applications such as emissive materials in optoelectronics, photosensitizers and dyes for biological imaging to name a few. ${ }^{1-6}$ Iridium(III) complexes offer numerous advantages such as high quantum efficiency, electrochemical stability and reversibility, accessibility by reliable and robust methods and tuneable colour of emission, which spans from sky blue to nearinfrared. ${ }^{7}$ Owing to the important spin-orbit coupling due to the presence of the heavy metal, all the molecules in the singlet excited state undergo nearly quantitatively an intersystem crossing to the triplet excited state. The emission of iridium(III) complexes emanates often from the radiative deactivation of the metal-toligand triplet excited state $\left({ }^{3} \mathrm{MLCT}^{*}\right)$ to the ground state. In many cases the luminescence is ascribed to the radiative deactivation of mixed triplet MLCT/LC excited states (LC: ligand centered)., ${ }^{7,8}$ Discrimination of the emission origin is accessible by the steady state and time resolved emission spectroscopy investigation, as well as with the help of calculations. ${ }^{9}$

Many applications need high emission quantum yield in the solid state, such as organic light-emitting devices (OLEDs) and

\footnotetext{
${ }^{a}$ Univ. Grenoble Alpes, CNRS, DCM, 38000 Grenoble, France.

E-mail: pierre-henri.lanoe@univ-grenoble-alpes.fr,

Frederique.loiseau@univ-grenoble-alpes.fr

${ }^{b}$ Univ. Grenoble Alpes, CNRS, Grenoble INP, Institut Néel, 38000 Grenoble, France

${ }^{c}$ Univ. Grenoble Alpes, CEA, CNRS, IRIG, CBM, F-38000 Grenoble, France

$\dagger$ Electronic supplementary information (ESI) available. CCDC 1981001. For ESI and crystallographic data in CIF or other electronic format see DOI: 10.1039/ d1cp03341g
}

light emitting electrochemical cells (LEECs). Unfortunately, the luminescence of chromophores, and particularly cyclometallated iridium(III) complexes, in neat solid is subject to dramatic quenching and the phenomenon is referred to as "aggregationcaused-quenching", ${ }^{10}$ For example, $\left[\operatorname{Ir}(\mathrm{ppy})_{3}\right]$ displays a photoluminescence quantum efficiency of $0.97^{11}$ in dilute solutions, whereas in neat film the value drops below $0.03^{12}$ and as an amorphous solid the complex is almost non luminescent. ${ }^{13}$ The drop of quantum efficiency from solution to solid has been assigned to self-quenching through intermolecular $\pi$-stacking interactions and triplet-triplet annihilation. ${ }^{6,14}$ The introduction of bulky groups, such as dimethylphenyl, mesityl, phenyl or $t$-butyl, to name a few, on the ligand framework ${ }^{15-18}$ and "shielding" of the metal center by macrocyclic ligands ${ }^{14,19}$ allow for inhibiting these interactions. For example, the iridium(III) complex from ref. 20, represented in Fig. 1 featuring the bulky 4,4'-di-tert-butyl-2,2'-bipyridine ligand, has unchanged<smiles></smiles>

Fig. 1 4,4'-Di-tert-butyl-2,2' -dipyridyl-bis[2-(2',4'-difluorophenyl)pyridine] iridium(III) isolated with hexafluorophosphate anion from ref. 20. 
photoluminescence efficiency from solution to the spin-coated film, with a QY of $68 \%$ in deaerated $\mathrm{CH}_{3} \mathrm{CN}$ and $72 \%$ in film. In contrast, some other complexes display low or almost no luminescence in solution and the "turning on" of the luminescence is triggered by aggregation either by the introduction of a nonsolvent or in the solid state (powder, neat spin-coated film or drop casted film). This behaviour has been called in different manners "enhanced phosphorescence emission in the solid state" (EPESS) and "aggregation-induced phosphorescence emission" (AIPE), ${ }^{6,21-23}$ depending on if the complex displays in dilute solution a weak emission or no detectable emission, respectively. In all these cases, the complex skeleton demonstrates flexibility in solution, and thus, the excitation energy is dispersed thermally. In the solid or aggregated state, the stiffening of the structure leads to "turning on" of emission.

Changes in the emission wavelength in the solid state are quite common particularly looking at the neat solid (powder, neat thin film and crystal). The large majority of the cationic iridium(III) complexes display a bathochromic shift in the solid state, ${ }^{17,23-34}$ whereas only few contributions report iridium(III) complexes displaying a hypsochromic shift. ${ }^{17,27,32-40}$ If bathochromic shifts could be easily rationalized by the presence of intermolecular interactions, such as $\pi-\pi$ interactions, ${ }^{14}$ blue shifted emission spectra in the solid state are less straightforward dealing with neat solid. In addition, the understanding of solid-state emission deals mainly with compounds displaying mechanochromism or piezochromism, which is the property of certain materials to change color by the application of pressure, usually through grinding. ${ }^{41}$ For example, the cationic $\operatorname{Ir}(\mathrm{III})$ complex with 2-phenylpyridine as a cyclometallating ligand and the 2-(5-phenyl-2-phenyl-1,2,4-triazol-3-yl)pyridine ancillary ligand (Fig. 2) displays blueshift emission in solid state, as well as mechanochromism. ${ }^{40}$ The "as synthesized" powder displays an emission centered at $471 \mathrm{~nm}$, whereas the emission in a diluted $\mathrm{CH}_{3} \mathrm{CN}$ solution is centered at $499 \mathrm{~nm}$. When grinding the "as synthesized" powder the emission displays a bathochromic shift and is similar to the emission observed in solution. Such a behavior was ascribed to phase transition from polycrystalline powder assessed by powder X-ray diffraction (PXRD) to amorphous phase. Nevertheless, the reason for the blue shift in the crystalline state was not stated.

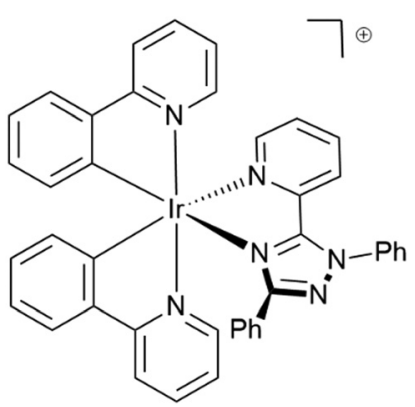

Fig. 2 Ir(III) complex with phenylpyridine as a cyclometallating ligand and the 2-(5-phenyl-2-phenyl-1,2,4-triazol-3-yl)pyridine isolated with $\mathrm{PF}_{6}$ anion, from ref. 40 .
Most of the cationic iridium complexes studied for lighting applications are derived from the archetypical 2,2'-dipyridylbis $\left[2^{\prime}, 4^{\prime}\right.$-phenylpyridine $]$ iridium(III) complex $\left(\left[(\mathrm{ppy})_{2} \mathrm{Irbpy}\right]^{+}\right.$, with ppy $=2^{\prime}, 4^{\prime}$-phenylpyridine and bpy $=2,2^{\prime}$-dipyridine), where the introduction of electron donating or electron withdrawing groups over the ligand allows for tuning efficiently the emission wavelength of the complex. ${ }^{42-45}$ For example, the archetypical [(ppy $)_{2}$ Irbpy $]^{+}$displays an emission centered at $585 \mathrm{~nm}\left(\mathrm{QY}=14 \%\right.$ in deaerated $\left.\mathrm{CH}_{3} \mathrm{CN}\right),{ }^{46}$ whereas the above mentioned complex with fluorine atoms (electron withdrawing effect) over the phenyl rings displays an emission centered at $512 \mathrm{~nm}\left(\mathrm{QY}=70 \%\right.$ in $\left.\mathrm{CH}_{3} \mathrm{CN}\right) .^{20}$ On the other hand, cationic complexes featuring 2-phenylbenzimidazole cyclometallating ligands are less common..$^{29,36,47-51}$ As advantages, this ligand gives several divergence points (i) the benzimidazole ring (phbnz), (ii) phenyl ring and (III) the substitution of the nitrogen atom in position 3 (Fig. 3 ) and its synthesis does not require the use of palladium-catalyzed cross-coupling reactions. ${ }^{52,53}$ The three positions could give access to a fine tuning of the emission properties and modification of the bulkiness of the final complex. In this contribution, we present a study of complex A with methoxy groups both in position 4 of the phenyl ring and position 5 of the benzimidazole moiety. The investigation of the photoluminescence properties in solution and solid samples (measured on crystals and on amorphous powder) revealed a hypsochromic shift in the crystal state. This behavior has been correlated with the organization of complex A in the crystals. Furthermore, the crystal structure of complex A has been determined, and PXRD has been performed.

\section{Methods}

\section{Synthesis of complex A}

Complex A has been synthesized following a two step procedure (Scheme 1) well described in the literature, ${ }^{17}$ that involved the formation of a dimer $\left[\left(\mathrm{C}^{\wedge} \mathrm{N}\right)_{2} \operatorname{Ir}(\mu-\mathrm{Cl})\right]_{2}$ by the methods described by Watts et al. ${ }^{54}$ and, in the second step, the introduction of the dimethylbipyridine (dmp) ligand. Complex $\mathbf{A}$ has been isolated

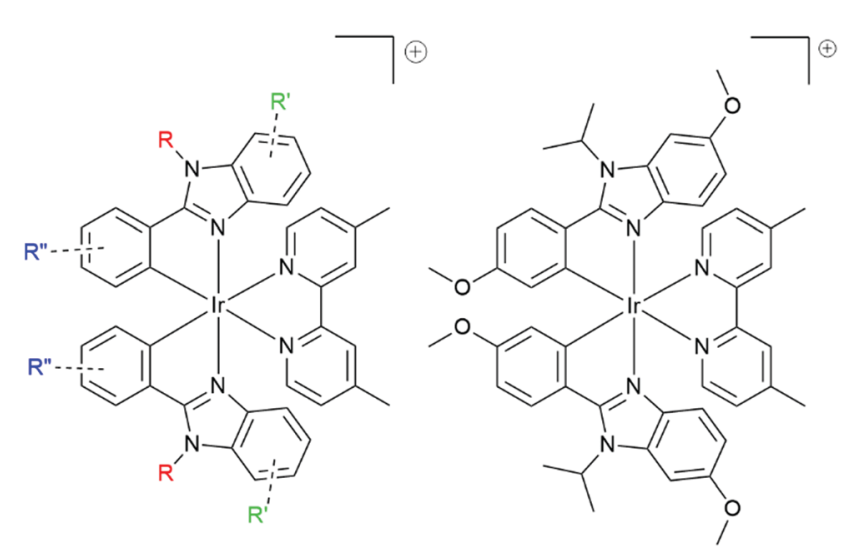

Fig. 3 Left: General structure of cationic iridium complexes featuring 2-phenylbenzimidazole cyclometallating ligand. Right: Complex A presented in the contribution. 


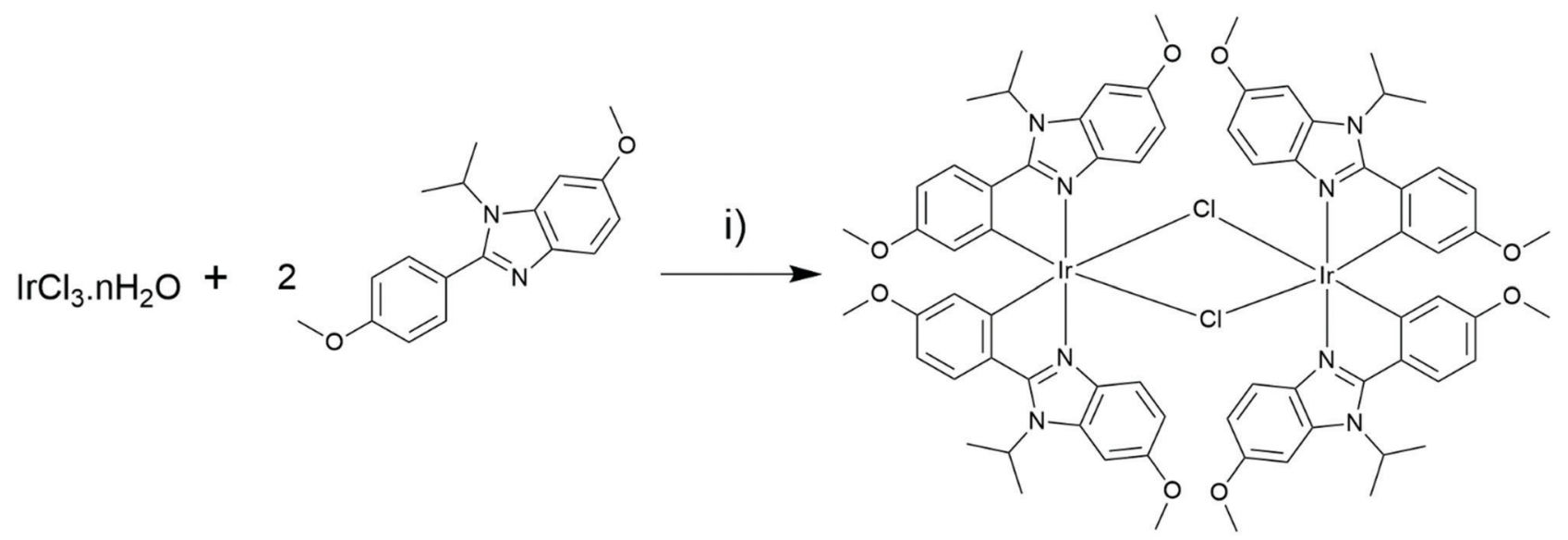

\section{Dimer}

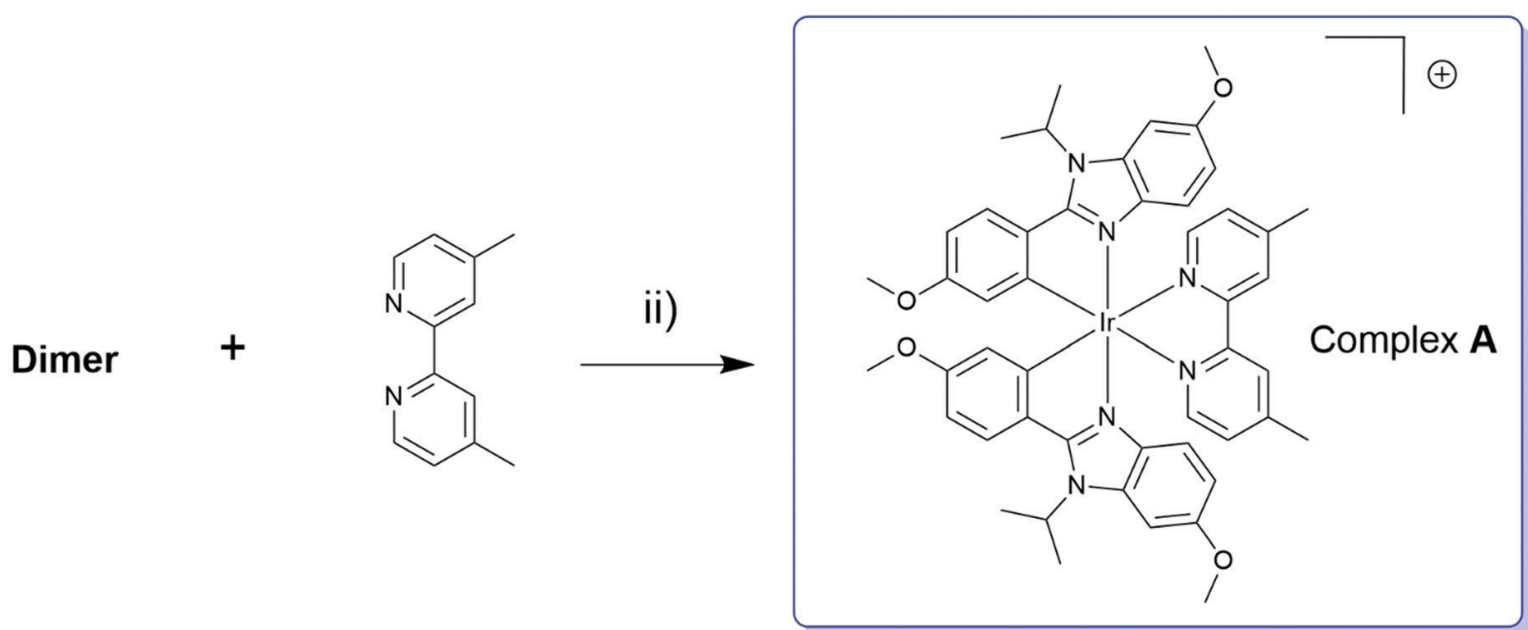

Scheme 1 Synthesis of complex A, (i) $\mathrm{H}_{2} \mathrm{O} / \mathrm{EtOEtOH}$ (1/3), refluxed overnight; (ii) $\mathrm{MeOH} / \mathrm{CH}_{2} \mathrm{Cl}_{2}$ (1/1) refluxed overnight under $\mathrm{Ar}$, then $\mathrm{KPF}$ (sat.).

after column chromatography followed by a rapid precipitation of the desired fraction with an overall yield of $67 \%$, and characterized by NMR $\left({ }^{1} \mathrm{H},{ }^{13} \mathrm{C},{ }^{19} \mathrm{~F}\right.$ and $\left.{ }^{31} \mathrm{P}\right)$, HRMS and elemental analysis. More details about the synthesis procedure and characterisation are available in the ESI. $\dagger$

\section{Preparation of the solid samples}

The amorphous powder (referred to as powder hereafter) was obtained by rapid precipitation of the material obtained after column chromatography by adding pentane in a concentrated solution of the complex in dichloromethane followed by filtration over Millipore ${ }^{\mathbb{R}}$ apparatus.

The crystals were obtained by slow vapor diffusion of diisopropylether in a concentrated solution in 1,2-dichloroethane. The process was repeatable and gave in each case dark orange crystals displaying green-yellow emission under UV-light. The resulting solids were collected indiscriminately and used for the emission spectroscopy experiments and for the PXRD measurements.

\section{Structural study}

Crystal structure determinations and refinements. The crystals display orange colour under daylight as the amorphous powder, but display a yellow emission under UV-light which differs from the orangey emission of the amorphous powder. The compound $\left(\left[\mathrm{C}_{48} \mathrm{H}_{50} \mathrm{IrN}_{6} \mathrm{O}_{4}\right]\left(\mathrm{PF}_{6}\right) \cdot 3 \mathrm{C}_{2} \mathrm{H}_{4} \mathrm{Cl}_{2}\right)$ crystallizes in the monoclinic $C 2 / c$ space group with the cell parameters $a=19.554(4) \AA, b=$ 22.055(4) $\AA, c=15.394(3) \AA$ and $\beta=117.07(3)^{\circ}, V=5911(2) \AA^{3}, Z^{\prime}=$ 4. A yellowish plate crystal $(0.13 \times 0.15 \times 0.30 \mathrm{~mm})$ was picked up, coated with a paraffin mixture and mounted with a nylon loop and centered on a Bruker-Nonius diffractometer equipped with an Incoatec high brilliance microsource with multilayer mirror monochromatized $\mathrm{Mo}(\mathrm{K} \alpha)$ radiation $(\lambda=0.71073 \AA)$ and an APEX II detector. Data were collected at $200 \mathrm{~K}$ with an Oxford Cryosystem to avoid the deterioration of the crystal that displays fragility when manipulated. Final cell parameters were obtained post refining the whole data. The collected reflections were corrected for Lorentz and polarization effects (EVAL14) and for absorption (SADABS). The resulting data were merged using 
XPREP. Using the OLEX 2 analysis package, the crystal structural solution was solved by the charge flipping method (Superflip) and refinement was performed by full-matrix least squares on $F^{2}$ (SHELX2013). All non-hydrogen atoms were refined anisotropically. $\mathrm{H}$ atoms were set geometrically, riding on the carrier atoms, with isotropic thermal parameters. $\mathrm{PF}_{6}$ anion and dichloroethane molecules displayed disorders which were treated using different positions with partial occupancy rates and restraints. The crystallographic details, selected bond lengths and angles are given in Table S1 (ESI $\dagger$ ) and Table 1 respectively (CCDC 1981001†).

\section{Powder X-ray diffraction details}

Powder X-ray diffraction (PXRD) was performed under ambient conditions using a Siemens D8 Advance diffractometer $(\mathrm{Cu} \mathrm{K} \alpha$ radiation, $40 \mathrm{~mA}, 40 \mathrm{kV}$ ) in the $3-60^{\circ} 2 \theta$ range with a $0.01^{\circ}$ step size and an acquisition time of $6 \mathrm{~s}$ per step.

\section{Photophysical characterisation}

The UV-visible spectra have been recorded on a Varian Carry 300 using $1 \mathrm{~cm}$ path length quartz cells. Steady state photoluminescence measurements of the liquid sample were carried out on a Horiba Fluoromax 4 using four wall quartz cuvettes with $1 \mathrm{~cm}$ path length and samples were degassed using the "freeze-pump-thaw" technique and for solid samples (crystals and powder) the spectra were acquired with a Horiba Fluorolog equipped with a "front face" acquisition set. The photoluminescence quantum yields (PLQY) were determined using $\operatorname{Ir}(\mathrm{ppy})_{3}$ in dichloromethane as the reference for liquid samples and PLQY of solid samples were determined using a GMP G8 integrating sphere fitted in a fluorolog. Time resolved photoluminescence measurements of liquid samples were performed on an Edinburgh Instruments nanosecond transient absorption LP920 equipped with a pump laser Quantel Brilliant emitting at $355 \mathrm{~nm}$.

\section{DFT and DFT:MM calculations}

All the DFT and DFT:MM calculations were carried out with the Gaussian 16 program, ${ }^{55}$ using the multilayer ONIOM method ${ }^{56}$ for the DFT:MM approach. The MN15 ${ }^{57}$ density functional was used with the double-zeta Def2SVP ${ }^{58,59}$ basis set for all atoms (which includes an effective core potential for $\operatorname{Ir}(\mathrm{III})$ for the QM part), while the $\mathrm{UFF}^{60}$ forcefield was used to describe $\mathrm{MM}$ atoms, using (and checking) the automatic assignment by the Gaussian program. All ONIOM calculations were performed with the "embed" keyword, in order to include the field of charges during the DFT SCF procedure, thus accounting directly for polarization of the wave function. The model of the crystal was built by creating a $7 \times 7 \times 7$ supercell starting from experimental positions using Mercury ${ }^{61}$ and Ambertools. ${ }^{62}$

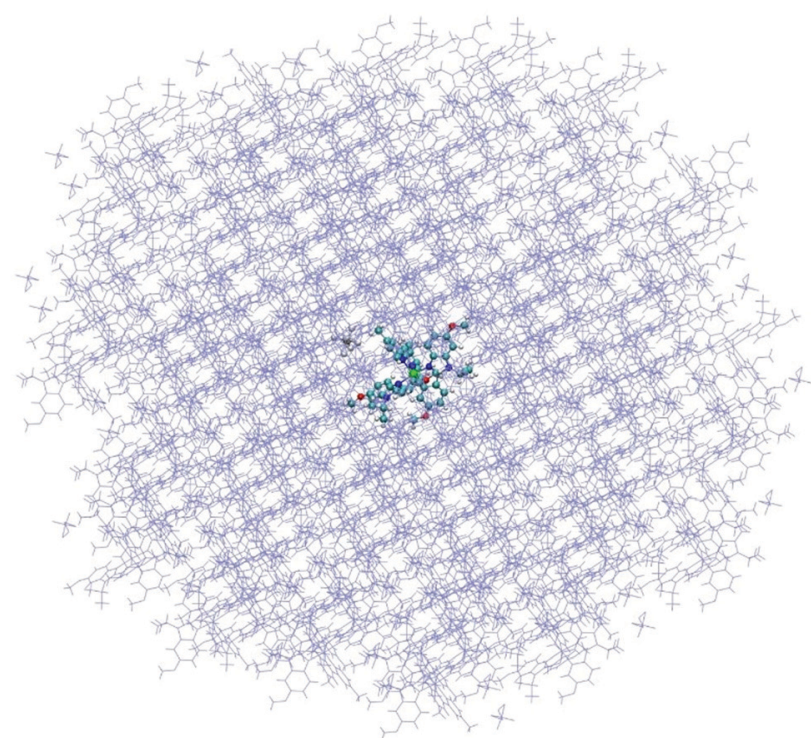

Fig. 4 Molecule and counterion embedded in a crystal part including all molecules with a part at a distance lower than or equal to $25 \AA$ from the molecule.

The central complex molecule was then selected and only molecules and counterions with at least one atom within a distance lower than or equal to $25 \AA$ from the selected molecule were kept. To ensure that the selection was electrically neutral, the same number of complexes and counterions (162 of each) was kept in the structure around the molecule of interest, representing a total of 18792 atoms (see Fig. 4).

This model has first been used to determine the charges of the surrounding MM layer. For that, we have used an approach similar to the one described by Bjornsson et al. ${ }^{63}$ In the first step, electrostatic charges were defined for the isolated molecule $+\mathrm{PF}_{6}{ }^{-}$system in its crystal geometry, using DFT. The CHELP ${ }^{64,65}$ and MK $^{66}$ ESP fitting methods were used. The charges obtained with these two methods differ notably from each other: for instance, only the CHELP method gave the Ir cation a positive charge. Nevertheless, very similar results were found for both, and only results obtained with the CHELP set of charges are shown in the present work. The set of charges thus determined has been attributed to the corresponding atoms in all molecules of the crystal model. A new set of charges determined on the central QM complex + counterion was determined within the field of charges created by the MM surroundings, and attributed to all the molecules. This procedure has been conducted iteratively for 50 steps. A rapid convergence (ca. 10 steps) to the 3rd digit was found and final atomic charges were taken as the average over the 20 last steps. Once the charges of the surroundings were determined, the model could be used to determine luminescence properties.

Table 1 Selected bond lengths and angles

\begin{tabular}{lllllll}
\hline $\operatorname{Ir} 1-\mathrm{C} 1(\AA)$ & $\operatorname{Ir} 1-\mathrm{N} 1(\AA)$ & $\operatorname{Ir}-\mathrm{N} 3(\AA)$ & $\mathrm{N}_{\mathrm{C}^{\wedge} \mathrm{N}^{\wedge}{ }^{\wedge} \mathrm{Ir}^{\wedge} \mathrm{N}_{\mathrm{C}^{\wedge} \mathrm{N}}\left({ }^{\circ}\right)}$ & $\mathrm{C}^{\wedge} \mathrm{N}$ bite angle $\left({ }^{\circ}\right)$ & $\mathrm{C}_{\mathrm{C}^{\wedge} \mathrm{N}^{\wedge} \operatorname{Ir}{ }^{\wedge} \mathrm{C}_{\mathrm{C}^{\wedge} \mathrm{N}}\left({ }^{\circ}\right)}$ & $\mathrm{dmp}$ bite angle $\left({ }^{\circ}\right)$ \\
\hline $2.024(2)$ & $2.037(2)$ & $2.126(2)$ & $171.38(11)$ & $79.30(9)$ & $90.15(13)$ & $77.47(11)$
\end{tabular}


In this new step, the $\mathrm{PF}_{6}{ }^{-}$counterion initially in the QM part for the determination of electrostatic charges was put in the MM part (hence keeping its crystallographic position) with the charges computed in the previous step; the charge of the phosphorus atom in this sole counterion (but not the surrounding ones) was adjusted to keep a neutral molecule and a total charge of -1 for the MM part and +1 for the central Ir complex.

The geometry of the central complex was optimized in its triplet state, all the MM atoms being kept frozen, thus accounting for both mechanical and electronic embedding.

We have considered that the emission process could be described as a vertical (adiabatic) transition, i.e. without change of geometry along the de-excitation process. Therefore, the energy of the complex in its singlet state, with the optimized geometry of the triplet state, has also been determined. The transition energy, denoted as $\Delta E_{\mathrm{T} \rightarrow \mathrm{S}}$, is determined as the energy difference between the two states and also used to compute the wavelength of the emitted photon during the vertical transition.

To compare the properties of the Ir complex in crystal to the ones in solvent or powder, a similar calculation was performed on the isolated complex: geometry optimization in the triplet state and single point calculation on the same geometry in the singlet state followed by the evaluation of the energy difference.

\section{Results and discussions}

\section{Crystal structure}

The iridium(III) and the $\mathrm{P}$ atom of the $\left(\left[\mathrm{IrL}_{2}(\mathrm{dmp})\right]\left(\mathrm{PF}_{6}\right)\right.$. $3 \mathrm{C}_{2} \mathrm{H}_{4} \mathrm{Cl}_{2}$ ) compound are lying on a 2 fold axis. The asymmetrical unit is constituted by a half Ir atom, a half dimethylbipyridine (dmp), one L ligand, a half $\mathrm{PF}_{6}$ anion and one and a half solvent molecules. The packing is represented along the three axes in Fig. S1 and S2 (ESI $\dagger$ ), in which it can be seen that cation chains (vide infra) are separated by the hexafluorophosphate anions. The complex displays a distorted octahedral geometry (Fig. 5 and Table 1). The angles formed by the nitrogen atoms from the cyclometallating ligands and the nitrogen atoms from the dmp are $\sim 99.4^{\circ}$ and $\sim 87.4^{\circ}$, respectively. Only the angle between the cyclometallating carbons around the Ir is almost ideal $\left(\sim 90.2^{\circ}\right)$. A distorted octahedral geometry is commonly observed in cyclometallated cationic iridium complexes, ${ }^{15,31,37,46,67-70}$ and it is also observed in the commonly called archetype complex $\left[\operatorname{Ir}(\mathrm{ppy})_{2} \mathrm{bpy}\right]^{+}{ }^{46}$ The coordinating nitrogen atoms from the benzimidazoles are in the expected trans position ${ }^{46}$ with each other $\left(\sim 171.4^{\circ}\right)$. As expected in the centrosymmetric space group, the $\Delta$ and $\Lambda$ isomers in alternance in the lattice and between two chains (Fig. 5 and 7) are observed and are formed during the cyclometallation step. ${ }^{71}$ The bite angles of the ligands are $\sim 77.5^{\circ}(\mathrm{dmp})$ and $\sim 79.3^{\circ}$ (phbnz), the latter being very similar to the phenylpyridine ligand bite angle $\left(\sim 80^{\circ}\right) .{ }^{46}$

The bond lengths (Table 1 ) of the coordinating atoms with Ir are $\sim 2.02 \AA, \sim 2.04 \AA$, and $\sim 2.13 \AA$ for the carbon atoms, the nitrogen atoms from the cyclometallating ligand and the nitrogen atoms from the dmp ligand, respectively. The bond

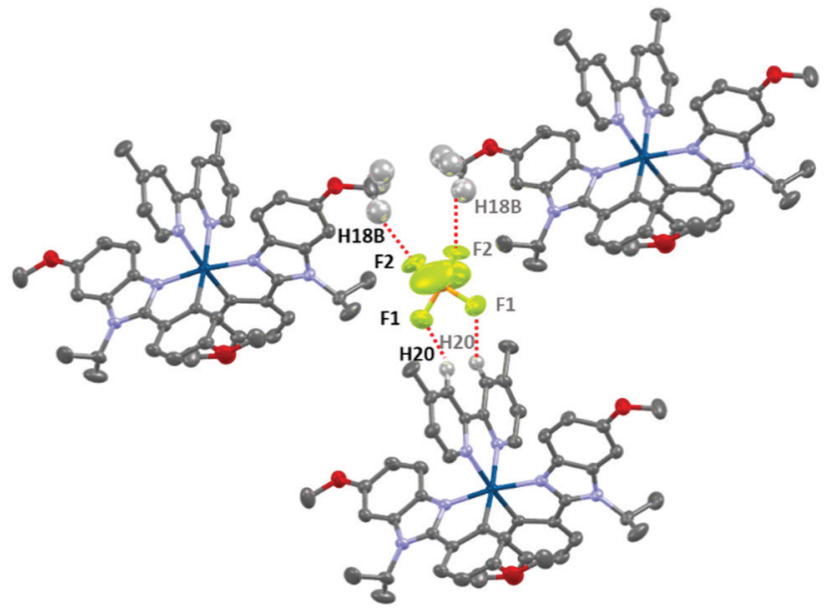

Fig. 5 Representation of the $\Lambda$ (left) and $\Delta$ (right) isomers of complex $\mathbf{A}$ with an ellipsoid drawn at $50 \%$ probability showing the label scheme (symmetry card for grey labels $(1-x, y, 3 / 2-z)$ ); hydrogen atoms have been omitted for clarity.

lengths are very similar to those encountered in [(ppy $)_{2}$ Irbpy $]^{+}$ with $2.01 \AA, 2.05 \AA$ and $2.13 \AA$, for Ir-C, Ir-N and Ir- $\mathrm{N}_{\text {bpy }}$ respectively. ${ }^{46}$ In addition, the $\mathrm{Ir}-\mathrm{N}_{\mathrm{bpy}}$ bonds are longer due to the so called trans effect, in agreement with the strong $\sigma$-donating ability of the carbon atoms. ${ }^{46}$ The dmp ligand is almost planar with a deviation of roughly $3.7^{\circ}$ between the two average plans of the pyridine rings, whereas the cyclometallating ligands deviate significantly with an angle of roughly $12^{\circ}$ between the average plans of the phenyl and of the benzimidazole moieties. The cyclometallation induced an obvious rigidification of the phenylbenzimidazole ligands that restricts the motion of the iso-propyl groups. Indeed, no disorder is observed for these groups. The $\mathrm{H} 5 \cdots \mathrm{H} 14 \mathrm{C}\left(\mathrm{CH}_{3}\right)_{2}$ distance is $1.973 \AA$, which is below the sum of the van der Waals radii (2.18 $)$. These interactions could be the origin of the important angles between the phenyl and the benzimidazole rings.

The complexes in the lattice are organized in chains and the $\mathrm{PF}_{6}$ anions, as well as solvent molecules $\left(\mathrm{ClCH}_{2} \mathrm{CH}_{2} \mathrm{Cl}\right)$, fill the space between them. Along the $b$ axis, one can observe an

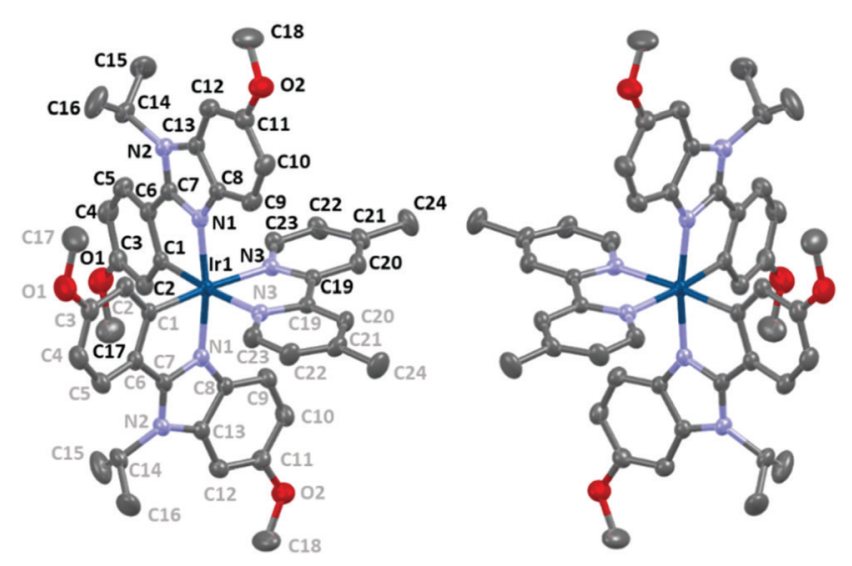

Fig. 6 Representation of the hydrogen bonds linking the $\mathrm{PF}_{6}$ anion and three cationic complexes $\mathbf{A}$; hydrogen atoms involved are highlighted. 
a

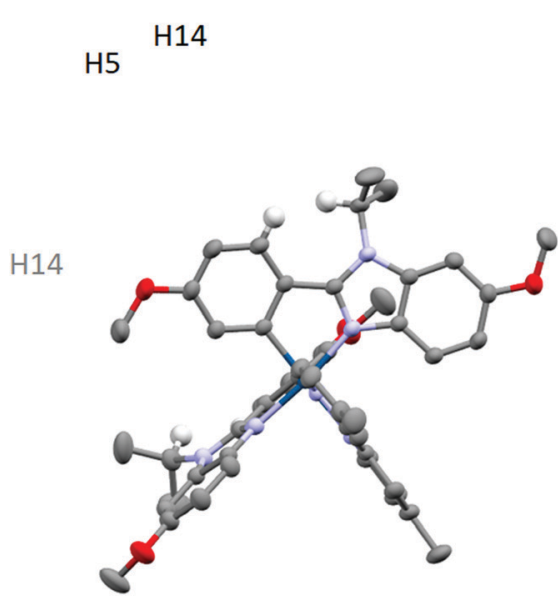

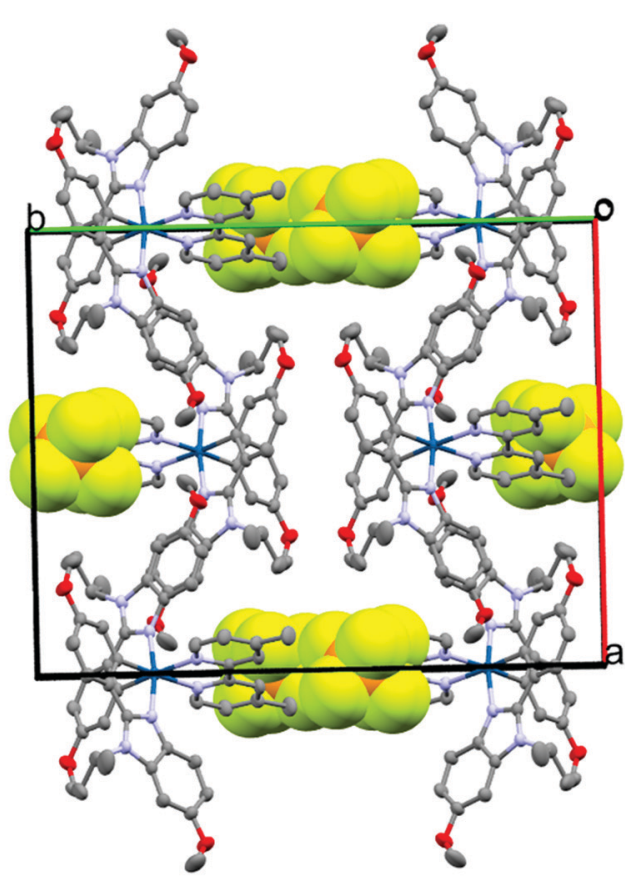

Fig. 7 (left) Crystal structure of complex $\mathbf{A}$ represented with an ellipsoid drawn at 50\% probability. $\mathrm{H} 5$ and $\mathrm{H} 14$ have been highlighted. (right) Crystal packing projection in the $(a, b)$ plane; hydrogen atoms have been omitted for clarity, $\mathrm{PF}_{6}$ anions are represented in space-fill, and dichloroethane solvent has been omitted.

Table 2 Hydrogen bond list

\begin{tabular}{lllll}
\hline Atoms (X, H, A) & X-H $(\AA)$ & $\mathrm{H} \cdots \mathrm{A}(\AA)$ & $\mathrm{X} \cdots \mathrm{A}(\AA)$ & $\begin{array}{l}\mathrm{H}-\mathrm{X} \cdots \mathrm{A} \\
\text { angles }\left(^{\circ}\right)\end{array}$ \\
\hline C20, H20, F1 & 0.95 & 2.49 & $3.378(4)$ & 156.3 \\
C9, H9, N3 & 0.95 & 2.63 & $3.369(4)$ & 135 \\
C18, H18, F2 & 0.98 & 2.49 & $3.362(15)$ & 148.6 \\
C22, H22, centroid (C12-C13) & 0.95 & 2.70 & 3.502 & 142.4 \\
& & & &
\end{tabular}

alternation in the orientation between two adjacent molecules, as well as in the chains (Fig. 7 and Fig. S3, S4, ESI $\dagger$ ). The complexes display intermolecular interactions and are organized in a somewhat catenary fashion along the ac direction. Within the chains, weak $\mathrm{H} \cdots \pi$ interactions are found between the hydrogen atom $\mathrm{H} 22$ from the dpm ligand and the $\mathrm{C} 12-\mathrm{C} 13$ bond from the benzimidazole moiety (Fig. S5, ESI $\dagger$ ). Counter ions deck chains through weak hydrogen bonding (Fig. 6 and Table 2). The interactions are displayed between the hydrogen atoms $\mathrm{H} 20$ of the dmp and fluorine atoms F1 from the counter ion and between the hydrogen atom H18B of the OMe group on the benzimidazole moiety and the fluorine atoms F2.\$ In addition, intramolecular hydrogen bonding is also observed between the H9 hydrogen atom riding on the $\mathrm{C} 9$ carbon atom of the cyclometallating ligand and nitrogen atom $\mathrm{N} 3$ of the dmp ligand (Fig. S6, ESI $†$ ). The angles formed by the hydrogen atoms, carbon atoms, and acceptor atoms (XHA angles ${ }^{72}$ ) are over $135^{\circ}$ and the $\mathrm{X} \cdots \mathrm{A}$ distances are in the range 3.6-3.8 $\AA$. The intermolecular

\$ The F2 atom presents disorder and it is defined with 2 positions F2A and F2B in cif file. interactions could be ascribed to weak hydrogen bonding with an electrostatic nature. ${ }^{72}$

\section{Powder X-ray diffraction}

The complex displays different colours in the powder and crystal forms, which may be related to polymorphism. ${ }^{23,36,38,73-75}$ The powder XRD pattern displays three undefined humps roughly centered at $10^{\circ}, 19^{\circ}$ and $37^{\circ}$ (Fig. 8). The absence of fine peaks demonstrates that the precipitated powder is amorphous. It is worth noting that the presented result differs from previous reports, where crystalline powders (PXRDs displayed sharp and intense diffraction peaks) were obtained with cationic iridium complexes either by evaporation of the solvents after column chromatography or by rapid recrystallization/precipitation. ${ }^{23,36,39,40,74,76}$ In contrast, the crystals, collected indiscriminately from the same batch of crystallization, display a different pattern from the powder (Fig. S8, ESI $\dagger$ ) with sharp peaks, which

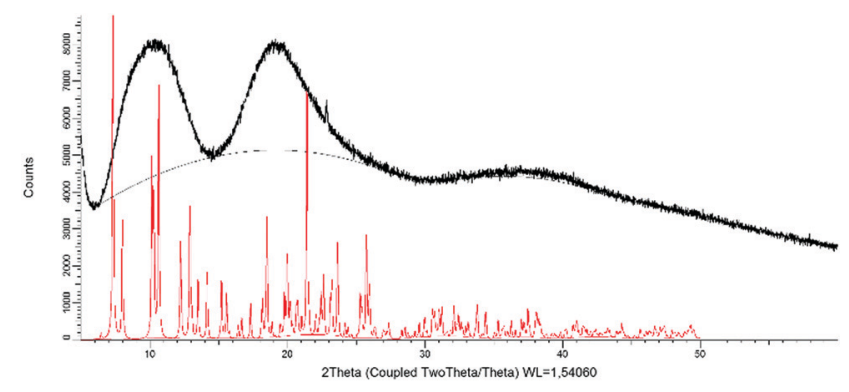

Fig. 8 Powder X-ray diffraction diagram obtained from precipitated powder (black) and the calculated pattern from the crystal structure (red). 
is similar to the calculated one from the crystal structure (Fig. S8, ESI $\dagger$ ).

\section{Absorption and emission spectroscopies}

The absorption and emission properties (steady state and time resolved) of the complex have been studied in both dichloromethane and acetonitrile under air equilibrated and deaerated conditions, regarding the emission. The spectra are displayed in Fig. 9 (left) and the quantum yields and lifetimes are gathered in Table 3.

The absorption spectrum displays in the UV region intense transitions, which can be ascribed to spin-allowed $\pi-\pi^{*}$ transition $\left({ }^{1} \mathrm{IL}\right)$ from the cyclometallating ligand and the ancillary ligand. Between $330 \mathrm{~nm}$ and $425 \mathrm{~nm}$, moderately intense absorption bands are attributed to spin-allowed charge transfer transitions, from the metal to the ligand $\left({ }^{1} \mathrm{MLCT}\right)$ and from the cyclometallating ligand to the ancillary ligand $\left({ }^{1}\right.$ LLCT).${ }^{7}$ The tail observed above $420 \mathrm{~nm}$ is due to direct spin-forbidden transitions leading to ${ }^{3}$ MLCT, permitted by the high spin-orbit coupling constant $\left(\zeta=3909 \mathrm{~cm}^{-1}\right)$ of the iridium core. ${ }^{7}$ The simulated spectrum, oscillator strength corresponding to the absorption bands and to the orbitals involved can be found in the ESI. $\dagger$
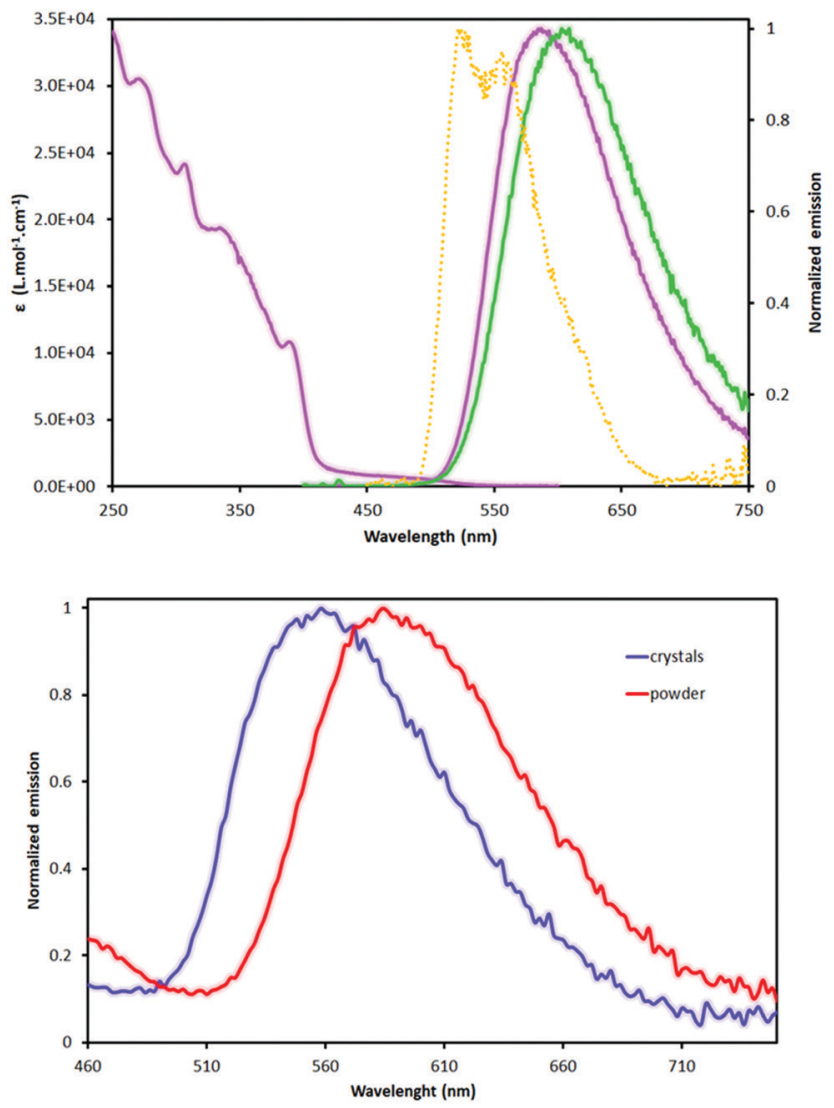

Fig. 9 Top: Absorption and normalized emission spectra in $\mathrm{CH}_{2} \mathrm{Cl}_{2}$ (purple), in $\mathrm{CH}_{3} \mathrm{CN}$ (green) and at $77 \mathrm{~K}$ in butyronitrile (yellow dotted line). Bottom: Normalized emission spectra from the powder (red) and the crystals (blue)
The complex displays a broad and unstructured orangey emission (Table 3 and Fig. 10) with a PLQY of $13 \%$ and $4 \%$, in $\mathrm{CH}_{2} \mathrm{Cl}_{2}$ and $\mathrm{CH}_{3} \mathrm{CN}$ respectively. The emission of the complex is sensitive to the presence of molecular oxygen with a quenching constant $\left(k_{\mathrm{Q}}\right)$ of the order of $3 \times 10^{9} \mathrm{M}^{-1} \mathrm{~s}^{-1}$ in both solvents. $\S$ The time resolved spectroscopies revealed a long lived emission in the range of hundreds of ns, which is typical of phosphorescent cationic iridium(III) complexes emitting in this region of the spectrum. ${ }^{16,45,77}$ The radiative deactivation constant $k_{\mathrm{r}}$ can be extracted from the emission data and it is of the order of $3 \times$ $10^{5} \mathrm{~s}^{-1}$, which corresponds to a radiative process emanating from the deactivation of a triplet metal-to-ligand-chargetransfer excited state $\left({ }^{3} \mathrm{MLCT}^{*}\right)$ to the ground state. ${ }^{7,8}$ The latter is corroborated by the broadness of the emission and the positive solvatochromism $\left(+510 \mathrm{~cm}^{-1}\right)$ of the emission, ${ }^{7,8}$ when comparing the emission in $\mathrm{CH}_{2} \mathrm{Cl}_{2}$ and $\mathrm{CH}_{3} \mathrm{CN}$. Finally, complex A displays at $77 \mathrm{~K}$ in glassy butyronitrile a structured emission with two peaks at $527 \mathrm{~nm}$ and $557 \mathrm{~nm}$ with a very long decay $(\sim 18 \mu \mathrm{s})$. This rigidochromism is typical of transition metal complexes submitted to a rigidification of the environment by a decrease of the temperature (vide infra) and is mainly observed when the emission arises from the radiative deactivation of the ${ }^{3} \mathrm{MLCT}^{*}$ to the ground state. Thus, the emission properties of complex A, emission shape, $k_{\mathrm{r}}$, positive solvatochromism and rigidochromism, indicate that the phosphorescence has for origin the radiative deactivation from the ${ }^{3}$ MLCT*$^{*}$; nonetheless, cyclometallated iridium(III) complexes are known to display emission from the radiative deactivation of the mixed excited state being mainly ${ }^{3} \mathrm{MLCT}^{*} /{ }^{3} \mathrm{LC}^{*^{7,8}}$ and the emission might be best described as emanating from the radiative deactivation to the ground state of such a mixed excited state with a predominance of the ${ }^{3} \mathrm{MLCT}^{*}$ as confirmed by the calculations (see ESI $\dagger$ ).

The solid-state emission has been explored in neat solid (i.e. amorphous powder and crystals), in steady state spectroscopy under an air atmosphere. Photos of the crystals and the powder displayed in Fig. 10 allow for visualizing with the naked eye the stark contrast of the emission of the amorphous phase and the crystal. Data are gathered in Table 3 and the spectra are displayed in Fig. 9. The powder was obtained by precipitation of complex A from a dichloromethane solution with pentane. Both solid forms of the complex (i.e. powder and crystals) display a broad and structureless emission in the visible region of the spectrum which is an indication that the emission should emanate from the same radiative process $\left({ }^{3} \mathrm{MLCT}^{*}{ }^{3} \mathrm{IL}^{*}\right)$ as in solution, which has been confirmed by the calculation (see ESI $\dagger$ ). Nevertheless, the emission spectrum of the powder is centered at $585 \mathrm{~nm}$ which is the same as the one observed in deaerated dichloromethane solution and in stark contrast the emission of the crystals displays a somewhat strong hypsochromic shift of $27 \mathrm{~nm}\left(798 \mathrm{~cm}^{-1}\right)$.

$\S$ The quenching rate constants are extracted from $\frac{\Phi_{0}}{\Phi}=1+\tau_{0} k_{\mathrm{Q}}\left[\mathrm{O}_{2}\right]$ with $\Phi_{0}$ being PLQY deaerated, $\Phi$ PLQY under air, $\tau_{0}$ deaerated lifetime and $\left[\mathrm{O}_{2}\right]$ the concentration of molecular oxygen in the solvent under normal pressure at r.t. 
Table 3 Luminescence data for crystals and powder samples under air and at room temperature and in diluted deaerated solutions at room temperature

\begin{tabular}{llllllll}
\hline & $\lambda_{\mathrm{em}}$ & $\Phi\left(\times 10^{-2}\right)$ & $\tau(\mathrm{ns})$ & $\Delta_{\mathrm{em}}{ }^{a}\left(\mathrm{~cm}^{-1}\right)$ & $k_{\mathrm{r}} \times 10^{5}\left(\mathrm{~s}^{-1}\right)$ & $k_{\mathrm{nr}} \times 10^{5}\left(\mathrm{~s}^{-1}\right)$ & $k_{\mathrm{Q}}\left[\mathrm{O}_{2}\right] \times 10^{9}\left(\mathrm{M}^{-1} \mathrm{~s}^{-1}\right)$ \\
\hline Powder & 585 & 5.4 & 1580 & 0 & - & - & - \\
Crystals & 558 & 7.2 & 1518 & -798 & - & - & - \\
$\mathrm{CH}_{2} \mathrm{Cl}_{2}$ & 585 & 13.0 & 570 & - & 3.0 & 20.0 & 3.5 \\
$\mathrm{CH}_{3} \mathrm{CN}$ & 603 & 4.0 & 260 & +510 & 3.6 & 93.0 & 2.9 \\
$77 \mathrm{~K}^{b}$ & $527,{ }^{c} 557$ & n.d. & 18440 & & &
\end{tabular}

${ }^{a}$ The shift in emission is determined taking the dichloromethane solution as the reference; positive values refer to a bathochromic shift and vice versa. ${ }^{b}$ In butyronitrile. ${ }^{c}$ Most intense emission band. Experimental decay curves are given in Fig. S8 (ESI).

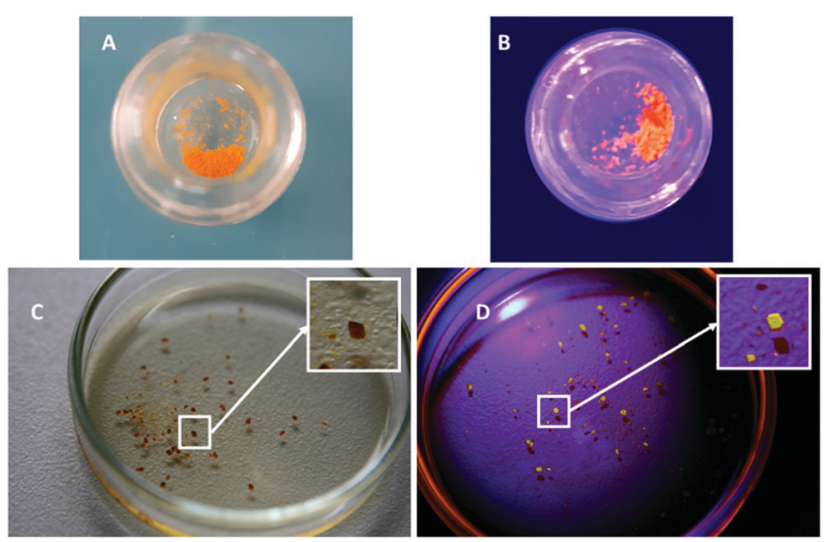

Fig. 10 Photography of the complex under daylight (A and C) and UVlight at $265 \mathrm{~nm}$ (B and D). (A and B) Show the amorphous phase. (C and D) Show isolated crystals. Dark dots correspond to the shadow of the crystals.

Such a shift solely in the crystal state is unusual (vide supra). This behaviour could be ascribed to rigidochromism which is a property of the transition metal complexes displaying a blue shifted emission when their solution environment becomes rigid, thus decreasing the stabilization of the emissive excited states, by lowering temperature ${ }^{78}$ or increasing the pressure. ${ }^{79}$ It is especially encountered with phosphorescence emanating from the radiative deactivation from the ${ }^{3} \mathrm{MLCT}^{*}$ to the ground state. Nevertheless, rigidochromism has been ascribed to a tetranuclear $\left[\mathrm{Au}_{2} \mathrm{Cu}_{2}\left(\mu-\left(\mathrm{PPh}_{2}\right)_{2} \mathrm{py}\right)_{2}(\mu-\mathrm{OH})\right]\left(\mathrm{PF}_{6}\right)_{3}$ cluster with a butterfly shaped metal core, that displays a very strong hypsochromic shift (172 nm, $4765 \mathrm{~cm}^{-1}$ ) from $\mathrm{CH}_{2} \mathrm{Cl}_{2}$ solution to powder at room temperature. ${ }^{80}$ This behaviour was attributed to the Jahn-Teller distortion in the lowest triplet excited state from linear to bent geometry around the gold(I) centers. Such an effect is unlikely to occur in octahedral $\mathrm{d}^{6}$ iridium(III) cyclometallated complexes ${ }^{81}$ and, in addition, the hypsochromic shift is observed solely in crystal for complex $\mathbf{A}$, thus ruling out rigidochromism. Regarding the supramolecular organisation in the crystal, no evidence of the presence of strong intermolecular interactions is found, and especially no $\pi-\pi$ stacking, that could lead to such a hypsochromic shift. In addition, the intrinsic octahedral geometry of complex A prevents the formation of $\mathrm{H}$-aggregates (or J-aggregates) both in solution and in solid state (crystal or powder). ${ }^{82,83}$ A hypsochromic shift has been reported in a dinuclear rhenium(I) complex ${ }^{84}$ and was ascribed to the local packing in the crystal and especially to the orientation of the molecular dipoles. In the case of complex A, a close look at the crystal lattice and especially at the projection in the ab plan (Fig. 5b) and the views displayed in Fig. S1-S4 (ESI $\dagger$ ) show that the complexes, and thus, the molecular dipoles, are oppositely oriented. Assuming that the excited state of the complex displays a higher molecular dipole moment than the ground state (in absolute value), it follows that the excited state could be destabilized. Consequently, the radiative deactivation of the excited state will be blue shifted in comparison with the solvated complexes. In addition, the crystal structure displays the presence of $\mathrm{PF}_{6}$ anion close to the dmp ligand, highlighted by weak hydrogen bonds (vide supra). One can predict that the negative charge borne by the counter ion may interfere also with the dipole moment and thus it would destabilize the excited state, leading to the observed hypsochromic shift in the crystal. However, in the amorphous powder, the complexes are randomly oriented, as shown by the PXRD and thus neither particular molecular dipole interaction nor interactions with the counter ions are present. To have a deeper understanding of the phenomena and to discriminate if rather the dipole-dipole interaction or the peculiar position of counter ion leads to the hypsochromic shift we have performed DFT and DFT:MM calculations.

\section{DFT and DFT:MM calculations}

To understand the hypsochromic effect observed in crystal, a series of DFT and DFT:MM calculations have been made, for the complex in both its singlet (ground state) and triplet (excited state) configurations, in a vacuum and embedded in a model of crystal. The structure was thus optimized at the MN15/Def2SVP level of theory for the isolated complex and MN15/Def2SVP:UFF levels of theory for the complex in crystal (see computational details), both for the singlet ground state (S) and triplet excited state (T). Using these models, we have first computed the $\lambda_{\max }$ of the emission associated with the triplet to singlet vertical luminescence transition. This value, denoted as $\Delta E_{\mathrm{T} \rightarrow \mathrm{S}}$, is computed as the difference between the energy of the optimized triplet structure $\left(E_{\mathrm{T}(\mathrm{T})}\right)$ and of the singlet structure $\left(E_{\mathrm{S}(\mathrm{T})}\right)$, with the triplet geometry $\left(\Delta E_{\mathrm{T} \rightarrow \mathrm{S}}=E_{\mathrm{T}(\mathrm{T})}-E_{\mathrm{S}(\mathrm{T})}\right)$ since the emission is considered to be associated with a vertical transition. Values obtained for the single complex and for the crystal model are reported in Table 4 and compared to the experimental results obtained in powder and in the crystal. The table compares both the $\Delta E_{\mathrm{T} \rightarrow \mathrm{S}(\mathrm{T})}$ and corresponding $\lambda_{\max }$ values.

Compared to experimental data from powder, the $\Delta E_{\mathrm{T} \rightarrow \mathrm{S}}$ given by the single complex model is overestimated by $0.09 \mathrm{eV}$. 
Table 4 Energy difference and corresponding $\lambda_{\max }$ of emission between the triplet and singlet states for the complex alone or in crystal. Experimental values are also provided for comparison purpose

\begin{tabular}{lll}
\hline & $\Delta E_{\mathrm{T} \rightarrow \mathrm{S}(\mathrm{T})}(\mathrm{eV})$ & $\lambda_{\max }(\mathrm{nm})$ \\
\hline Single complex model & 2.21 & 561 \\
Crystal model & 2.46 & 504 \\
Amorphous powder (exp) & 2.12 & 585 \\
Crystals (exp) & 2.22 & 558
\end{tabular}

Comparing the crystal model and experimental results also shows an overestimation of $0.24 \mathrm{eV}$. However, calculations account for the hypsochromic effect with an overestimated decrease of the $\lambda_{\max }$ of $-57 \mathrm{~nm}(561 \mathrm{~nm}$ to $504 \mathrm{~nm})$, to be compared to the $27 \mathrm{~nm}$ obtained experimentally. We thus consider that our model is able to reproduce the experimental findings and is therefore suitable to investigate the actual nature of the influence of the crystal. This influence of the surrounding can be split into two main components: a steric effect that can modify the complex structure upon crystallization and a polarization effect, due to the charges of surrounding molecules. Both have been evaluated using the DFT:MM model.

The mechanical influence was first evaluated by comparing the geometries of the triplet structures (excited states giving rise to emission) optimized in a vacuum and in the crystal. A structure alignment shows very similar geometries, with a computed RMSD of only $0.24 \AA$. This limited influence of the crystal on the structure of the complex is consistent with quite a "rigid" complex structure. One can specifically remark that, when putting the complex out of the crystal, the four Ir-N distances do not vary while the two Ir-C bonds marginally shrink from $2.02 \AA$ to $2.00 \AA$ A. Since the crystalline environment keeps the geometry of the complex essentially unchanged compared to the one of the complex alone, one can thus deduce that the hypsochromic effect observed might be rather due to the polarization effects of the crystalline structure.

To evaluate this effect, the $\Delta E_{\mathrm{T} \rightarrow \mathrm{S}}$ for the complex in its crystal geometry, but without the surrounding charges, has been compared to the one obtained in the complete model. A value of $2.19 \mathrm{eV}$ was found, very similar (even smaller) to the value found in a vacuum. This thus confirms that the observed hypsochromism is due to the polarization effects of the crystalline environment.

In order to understand this polarizing effect of the surroundings and especially discriminate between long- and short-range effects, the $\Delta E_{\mathrm{T} \rightarrow \mathrm{S}}$ has been computed for a smaller crystal model in which only the first neighbours of the complex (other complexes and counterions all at the MM level) were kept. The value found, 2.48 $\mathrm{eV}$, is essentially the same as in the "big" model, showing an exclusively short-range effect. Finally, the calculation of $\Delta E_{\mathrm{T} \rightarrow \mathrm{S}(\mathrm{T})}$ was performed for a complex in interaction with either the nearest equivalent complex or the nearest $\mathrm{PF}_{6}{ }^{-}$counterion. The presence of the nearest complex only (at the MM level) yields a $\Delta E_{\mathrm{T} \rightarrow \mathrm{S}}$ of $2.14 \mathrm{eV}$, very similar to the result in a vacuum, thus discarding a strong complex/complex interaction. On the opposite, the presence of the nearest counterion only yields a $\Delta E_{\mathrm{T} \rightarrow \mathrm{S}(\mathrm{T})}$ of $2.41 \mathrm{eV}$, almost unchanged compared to the largest crystal model. This result unambiguously proves that the hypsochromic effect is due to the presence of a negatively charged counterion located near each complex in the crystal. Interestingly, even the replacement of $\mathrm{PF}_{6}{ }^{-}$with a negative point charge at the position of the $\mathrm{P}$ atom yields a hypsochromic shift of $2.43 \mathrm{eV}$. This $\mathrm{PF}_{6}{ }^{-}$anion is positioned at a peculiar place and interacts strongly through hydrogen bonding with $\mathrm{H} 20$ of the dmp ligand (vide supra) and the negative charge of the anion destabilizes the excited state. Indeed, the dipole moment in this complex is roughly oriented from the electron rich iridium toward the electron poor dmp ligand in the ground state. ${ }^{85,86}$ In the excited state the electron density is inverted, and so is the dipole moment. Due to its specific position, the $\mathrm{PF}_{6}$ anion will more "perturbate" the excited state than the ground state, thus leading to an increase of the $\Delta E_{\mathrm{T} \rightarrow \mathrm{S}}$ and a hypsochromic shift of the emission in crystals. To illustrate this hypothesis, we have compared the dipole moments from DFT calculations, for the complex in its singlet and triplet states, in the presence or absence of a negative point charge of $-e$ at the position of the $\mathrm{P}$ atom, all using the geometry from the crystal. Because the complex is positively charged, its dipole is gauge-dependent (depends on position and orientation). A special care has thus been taken to carry out calculations on the same structure (same geometry and same orientation) with or without the charge, in the triplet and singlet states.

Fig. 11 represents the dipole as an arrow starting from the origin. The scale is 1 Debye for one A. The orange arrow is for the complex in its singlet state, without charge, and green when in triplet without charge. In the presence of the charge, the dipole for the singlet state is shown in red and the one for the triplet state is in blue. As stated, the singlet and triplet structures have opposite dipoles when the complex is isolated, both along the $\mathrm{C} 2$ rotation axis. In the presence of the charge (blue sphere), both the dipoles (red: singlet and blue: triplet) are modified and now partially point towards the negative

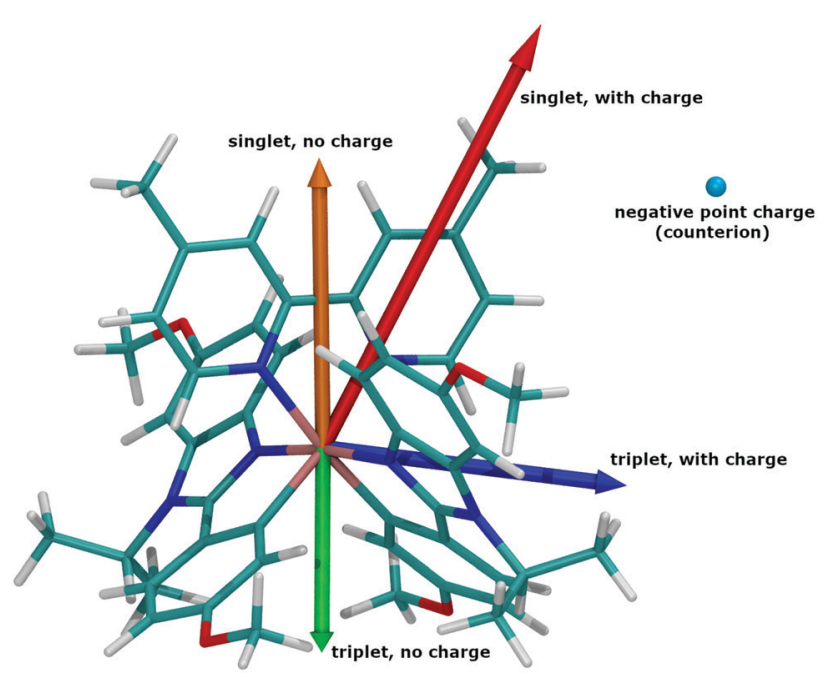

Fig. 11 Representation of the dipole of the complex at the origin without counterion (orange: singlet, green: triplet) or in presence of a negative charge at the position of the $\mathrm{P}$ atom of the counterion (red: singlet, blue: triplet). 
charge. As shown in Fig. 11, the triplet dipole is more affected than the singlet one, consistent with a more perturbed electron structure and a $\Delta E_{\mathrm{T} \rightarrow \mathrm{S}}$ value increase in the presence of the negative charge, i.e., in the crystal structure.

\section{Conclusions}

In summary, we have reported the synthesis and the characterization of a new cationic iridium(III) complex featuring two 1-( $p$ methoxyphenyl)-5-methoxybenzimidazole cyclometallating ligands and a dimethylbipyridine ancillary ligand. The single crystal structure and the powder X-ray diffraction have been presented. The photophysical studies of the complex point out a strong change in the emission wavelength of the complex between $\mathrm{CH}_{2} \mathrm{Cl}_{2}$ solution and the amorphous powder in comparison with crystals, with a hypsochromic shift of the order $800 \mathrm{~cm}^{-1}$, whereas (i) the majority of cationic iridium complexes display a bathochromic shift from solution to neat solid, and (ii) the few observed hypsochromic shifts are on average $600 \mathrm{~cm}^{-1}$. The study of the single crystal XRD and in particular the packing of the molecules in the lattice suggest that the observed shift can be explained by the destabilizing effect of the neighbouring counterion in the crystal on the dipole moment of the complexes. This result is supported by the calculation that fits very well the experimental data. These results highlight how packing can perturb the photophysical properties of the molecules, even in the absence of particularly short interactions.

\section{Conflicts of interest}

There are no conflicts to declare.

\section{Acknowledgements}

The authors thank the CNRS and Universite de Grenoble Alpes for their support. This work benefited from state aid managed by the National Research Agency under the "Investments for the future" and the "Investissements d'avenir" program bearing the reference ANR-15-IDEX-02”. E. Martinez-Vollbert has benefited from a CONACYT program (707986). This work was partially supported by CBH-EUR-GS (ANR-17-EURE-0003). The NanoBio ICMG (UAR 2607) is acknowledged for providing facilities for mass spectrometry (A. Durand, L. Fort and R. Gueret), elemental analyses (M. Fayolle) and single crystal X-ray diffraction (N. Altounian).

The solid-state emission measurements have been performed in the "Laboratoire de Chimie" (UMR-5182) at the “Ecole Nationnale Supérieure de Lyon” (ENSL).

\section{References}

1 W. C. H. Choy, W. K. Chan and Y. Yuan, Adv. Mater., 2014, 26, 5368-5399.

2 K. K.-W. Lo, Acc. Chem. Res., 2015, 48, 2985-2995.
3 Y. J. Yuan, Z. T. Yu, D. Q. Chen and Z. G. Zou, Chem. Soc. Rev., 2017, 46, 603-631.

4 C. K. Prier, D. a Rankic and D. W. C. MacMillan, Chem. Rev., 2013, 113, 5322-5363.

5 J. H. Shon and T. S. Teets, ACS Energy Lett., 2019, 4, 558-566.

6 Q. Zhao, L. Li, F. Li, M. Yu, Z. Liu, T. Yi and C. Huang, Chem. Commun., 2008, 685-687.

7 L. Flamigni, A. Barbieri, C. Sabatini, B. Ventura and F. Barigelletti, Photochemistry and Photophysics of Coordination Compounds II, 2007, pp. 143-203.

8 K. P. S. Zanoni, R. L. Coppo, R. C. Amaral and N. Y. Murakami Iha, Dalton Trans., 2015, 44, 14559-14573.

9 P. A. Scattergood, A. M. Ranieri, L. Charalambou, A. Comia, D. A. W. Ross, C. R. Rice, S. J. O. Hardman, J.-L. Heully, I. M. Dixon, M. Massi, F. Alary and P. I. P. Elliott, Inorg. Chem., 2020, 59, 1785-1803.

10 X. Yan, H. Wang, C. E. Hauke, T. R. Cook, M. Wang, M. L. Saha, Z. Zhou, M. Zhang, X. Li, F. Huang and P. J. Stang, J. Am. Chem. Soc., 2015, 137, 15276-15286.

11 T. Sajoto, P. I. Djurovich, A. B. Tamayo, J. Oxgaard, W. A. Goddard and M. E. Thompson, J. Am. Chem. Soc., 2009, 131, 9813-9822.

12 Y. Kawamura, K. Goushi, J. Brooks, J. J. Brown, H. Sasabe and C. Adachi, Appl. Phys. Lett., 2005, 86, 71104.

13 Y. Kawamura, H. Sasabe and C. Adachi, Jpn. J. Appl. Phys., 2004, 43, 7729-7730.

14 N. Komiya, M. Okada, K. Fukumoto, D. Jomori and T. Naota, J. Am. Chem. Soc., 2011, 133, 6493-6496.

15 X. Wang, S. Wang, F. Pan, L. He and L. Duan, Inorg. Chem., 2019, 58, 12132-12145.

16 E. C. Constable, C. E. Housecroft, G. E. Schneider, J. A. Zampese, H. J. Bolink, A. Pertegás and C. RoldanCarmona, Dalton Trans., 2014, 43, 4653-4667.

17 A. F. Henwood, A. K. Pal, D. B. Cordes, A. M. Z. Slawin, T. W. Rees, C. Momblona, A. Babaei, A. Pertegás, E. Ortí, H. J. Bolink, E. Baranoff and E. Zysman-Colman, J. Mater. Chem. C, 2017, 5, 9638-9650.

18 G. Rajendra Kumar and P. Thilagar, Inorg. Chem., 2016, 55, 12220-12229.

19 N. Komiya, M. Okada, K. Fukumoto, K. Kaneta, A. Yoshida and T. Naota, Chem. - Eur. J., 2013, 19, 4798-4811.

20 H. J. Bolink, E. Coronado, R. D. Costa, N. Lardiés and E. Ortí, Inorg. Chem., 2008, 47, 9149-9151.

21 V. Sathish, A. Ramdass, P. Thanasekaran, K. L. Lu and S. Rajagopal, J. Photochem. Photobiol., C, 2015, 23, 25-44.

22 H. Wu, T. Yang, Q. Zhao, J. Zhou, C. Li and F. Li, Dalton Trans., 2011, 40, 1969-1976.

23 J. Han, K. Tang and S. Cheng, Inorg. Chem. Front., 2020, 7, 786-794.

24 H.-C. Su, H.-F. Chen, F.-C. Fang, C.-C. Liu, C.-C. Wu, K.-T. Wong, Y.-H. Liu and S.-M. Peng, J. Am. Chem. Soc., 2008, 130, 3413-3419.

25 L. He, L. Duan, J. Qiao, G. Dong, L. Wang and Y. Qiu, Chem. Mater., 2010, 22, 3535-3542.

26 L. He, D. Ma, L. Duan, Y. Wei, J. Qiao, D. Zhang, G. Dong, L. Wang and Y. Qiu, Inorg. Chem., 2012, 51, 4502-4510. 
27 S. Evariste, M. Sandroni, T. W. Rees, C. Roldán-Carmona, L. Gil-Escrig, H. J. Bolink, E. Baranoff and E. ZysmanColman, J. Mater. Chem. C, 2014, 2, 5793.

28 K. P. S. Zanoni, M. S. Sanematsu and N. Y. Murakami Iha, Inorg. Chem. Commun., 2014, 43, 162-164.

29 G. G. Shan, H. Bin Li, Z. C. Mu, D. X. Zhu, Z. M. Su and Y. Liao, J. Organomet. Chem., 2012, 702, 27-35.

30 Y. Lan, G. Li, Z. Wang, Y. He, Y. Liu and L. He, Dyes Pigm., 2017, 144, 158-167.

31 K. J. Suhr, L. D. Bastatas, Y. Shen, L. A. Mitchell, G. A. Frazier, D. W. Taylor, J. D. Slinker and B. J. Holliday, Dalton Trans., 2016, 45, 17807-17823.

32 E. Matteucci, A. Baschieri, A. Mazzanti, L. Sambri, J. Ávila, A. Pertegás, H. J. Bolink, F. Monti, E. Leoni and N. Armaroli, Inorg. Chem., 2017, 56, 10584-10595.

33 C. Hierlinger, D. B. Cordes, A. M. Z. Slawin, D. Jacquemin, V. Guerchais and E. Zysman-Colman, Dalton Trans., 2018, 47, 10569-10577.

34 L. P. Li, S. Y. Yao, Y. L. Ou, L. Q. Wei and B. H. Ye, Organometallics, 2017, 36, 3257-3265.

35 J. D. Slinker, A. A. Gorodetsky, M. S. Lowry, J. Wang, S. Parker, R. Rohl, S. Bernhard and G. G. Malliaras, J. Am. Chem. Soc., 2004, 126, 2763-2767.

36 H. Cao, H. Sun, G. Shan, Y. Wu, Z. Su and Y. Liao, J. Mater. Chem. C, 2015, 2341-2349.

37 K. J. Suhr, L. D. Bastatas, Y. Shen, L. A. Mitchell, B. J. Holliday and J. D. Slinker, ACS Appl. Mater. Interfaces, 2016, 8, 8888-8892.

38 K. Traskovskis, V. Kokars, S. Belyakov, N. Lesina, I. Mihailovs and A. Vembris, Inorg. Chem., 2019, 58, 4214-4222.

39 G. G. Shan, H. Bin Li, H. T. Cao, D. X. Zhu, P. Li, Z. M. Su and Y. Liao, Chem. Commun., 2012, 48, 2000-2002.

40 G. Shan, H.-B. Li, D.-X. Zhu, Z.-M. Su and Y. Liao, J. Mater. Chem., 2012, 22, 12736-12744.

41 Z. Chi, X. Zhang, B. Xu, X. Zhou, C. Ma, Y. Zhang, S. Liu and J. Xu, Chem. Soc. Rev., 2012, 41, 3878-3896.

42 C. E. Housecroft and E. C. Constable, Coord. Chem. Rev., 2017, 350, 155-177.

43 L. He, Y. Lan, D. Ma, X. Song and L. Duan, J. Mater. Chem. C, 2018, 6, 1509-1520.

44 C. D. Ertl, C. Momblona, A. Pertegás, J. M. JunqueraHernández, M. G. La-Placa, A. Prescimone, E. Ortí, C. E. Housecroft, E. C. Constable and H. J. Bolink, J. Am. Chem. Soc., 2017, 139, 3237-3248.

45 A. F. Henwood and E. Zysman-Colman, Top. Curr. Chem., 2016, 374, 36.

46 R. D. Costa, E. Ortí, H. J. Bolink, S. Graber, S. Schaffner, M. Neuburger, C. E. Housecroft and E. C. Constable, Adv. Funct. Mater., 2009, 19, 3456-3463.

47 Y. Jiao, M. Li, N. Wang, T. Lu, L. Zhou, Y. Huang, Z. Lu, D. Luo and X. Pu, J. Mater. Chem. C, 2016, 4, 4269-4277.

48 T. Yu, F. Yang, X. Chen, W. Su and Y. Zhao, New J. Chem., 2017, 41, 2046-2054.

49 H.-T. T. Mao, C.-X. X. Zang, G.-G. G. Shan, H.-Z. Z. Sun, W.-F. F. Xie and Z.-M. M. Su, Inorg. Chem., 2017, 56, 9979-9987.
50 J. E. Yarnell, P. De La Torre and F. N. Castellano, Eur. J. Inorg. Chem., 2017, 1-9.

51 J.-H. Zhao, Y.-X. Hu, Y. Dong, X. Xia, H.-J. Chi, G.-Y. Xiao, X. Li and D.-Y. Zhang, New J. Chem., 2017, 41, 1973-1979.

52 J. F. Lemonnier, L. Guénée, C. Beuchat, T. A. Wesolowski, P. Mukherjee, D. H. Waldeck, K. A. Gogick, S. Petoud and C. Piguet, J. Am. Chem. Soc., 2011, 133, 16219-16234.

53 N. M. Shavaleev, S. V. Eliseeva, R. Scopelliti and J. C. G. Bünzli, Chem. - Eur. J., 2009, 15, 10790-10802.

54 S. Sprouse, K. A. King, P. J. Spellane and R. J. Watts, J. Am. Chem. Soc., 1984, 106, 6647-6653.

55 D. J. Frisch, M. J. Trucks, G. W. Schlegel, H. B. Scuseria, G. E. Robb, M. A. Cheeseman, J. R. Scalmani, G. Barone, V. Petersson, G. A. Nakatsuji, H. Li, X. Caricato, M. Marenich, A. V. Bloino, J. Janesko, B. G. Gomperts, R. Mennucci and B. Hratch, Gaussian 09, Revision E.01, 2016.

56 S. Dapprich, I. Komáromi, K. S. Byun, K. Morokuma and M. J. Frisch, THEOCHEM, 1999, 461-462, 1-21.

57 H. S. Yu, X. He, S. L. Li and D. G. Truhlar, Chem. Sci., 2016, 7, 5032-5051.

58 F. Weigend and R. Ahlrichs, Phys. Chem. Chem. Phys., 2005, 7, 3297-3305.

59 F. Weigend, Phys. Chem. Chem. Phys., 2006, 8, 1057-1065.

60 A. K. Rappe, C. J. Casewit, K. S. Colwell, W. A. Goddard and W. M. Skiff, J. Am. Chem. Soc., 1992, 114, 10024-10035.

61 C. F. Macrae, I. Sovago, S. J. Cottrell, P. T. A. Galek, P. Mccabe, E. Pidcock, M. Platings, G. P. Shields, J. S. Stevens, M. Towler and P. A. Wood, J. Appl. Crystallogr., 2020, 53, 226-235.

62 D. A. Case, K. Belfon, I. Y. Ben-Shalom, S. R. Brozell, S. D. Cerutti, T. E. Cheatham, V. W. D. Cruzeiro, A. T. Darden, R. E. Duke, G. Giambasu, M. K. Gilson, H. Gohlke, A. W. Goetz, R. Harris, S. Izadi, S. A. Izmailov, K. Kasavajhala, A. Kovalenko, R. Krasny, T. Kurtzman, T. S. Lee, S. Le Grand, P. Li, C. Lin, J. Liu, T. Luchko, R. Luo, V. Man, K. M. Merz, Y. Miao, O. Mikhailovskii, G. Monard, H. Nguyen, A. Onufriev, F. Pan, S. Pantano, R. Qi, D. R. Roe, A. Roitberg, C. Sagui, S. Schott-Verdugo, J. Shen, C. L. Simmerling, N. R. Skrynnikov, J. Smith, J. Swails, R. C. Walker, J. Wang, L. Wilson, R. M. Wolf, X. Wu, Y. Xiong, Y. Xue, D. M. York and P. A. Kollman, Amber 2021, University of California, San Francisco, 2021.

63 R. Bjornsson and M. Bühl, J. Chem. Theory Comput., 2012, 8, 498-508.

64 L. E. Chirlian and M. M. Francl, J. Comput. Chem., 1987, 8, 894-905.

65 C. M. Breneman and K. B. Wiberg, J. Comput. Chem., 1990, 11, 361-373.

66 U. C. Singh and P. A. Kollman, J. Comput. Chem., 1984, 5, 129-145.

67 S. I. Bezzubov, Y. M. Kiselev, A. V. Churakov, S. A. Kozyukhin, A. A. Sadovnikov, V. A. Grinberg, V. V. Emets and V. D. Doljenko, Eur. J. Inorg. Chem., 2016, 347-354.

68 E. Baranoff, H. J. Bolink, E. C. Constable, M. Delgado, D. Häussinger, C. E. Housecroft, M. K. Nazeeruddin, 
M. Neuburger, E. Ortí, G. E. Schneider, D. Tordera, R. M. Walliser and J. A. Zampese, Dalton Trans., 2013, 42, 1073-1087.

69 M. Martínez-Alonso, J. Cerdá, C. Momblona, A. Pertegás, J. M. Junquera-Hernández, A. Heras, A. M. Rodríguez, G. Espino, H. Bolink and E. Ortí, Inorg. Chem., 2017, 56, 10298-10310.

70 K. A. Phillips, T. M. Stonelake, K. Chen, Y. Hou, J. Zhao, S. J. Coles, P. N. Horton, S. J. Keane, E. C. Stokes, I. A. Fallis, A. J. Hallett, S. P. O'Kell, J. M. Beames and S. J. A. Pope, Chem. - Eur. J., 2018, 24, 8577-8588.

71 D. G. Congrave, Y. Ting Hsu, A. S. Batsanov, A. Beeby and M. R. Bryce, Organometallics, 2017, 36, 981-993.

72 T. Steiner, Angew. Chem., Int. Ed., 2002, 41, 48-76.

73 D. Avobenzone, G. Zhang, J. Lu, M. Sabat and C. L. Fraser, J. Am. Chem. Soc., 2010, 132, 2160-2162.

74 T. F. Mastropietro, Y. J. Yadav, E. I. Szerb, A. M. Talarico, M. Ghedini and A. Crispini, Dalton Trans., 2012, 41, 8899-8907.

75 B. Xu, J. He, Y. Mu, Q. Zhu, S. Wu, Y. Wang, Y. Zhang, C. Jin, C. Lo, Z. Chi, A. Lien, S. Liua and J. Xu, Chem. Sci., 2015, 3236-3241.

76 Y. You, H. S. Huh, K. S. Kim, S. W. Lee, D. Kim and S. Y. Park, Chem. Commun., 2008, 3998-4000.
77 K. Hasan, A. K. Bansal, I. D. W. Samuel, C. RoldánCarmona, H. J. Bolink and E. Zysman-Colman, Sci. Rep., 2015, 5, 1-16.

78 A. J. Lees, Comments Inorg. Chem., 1995, 17, 319-346.

79 D. Tran, J. L. Bourassa and P. C. Ford, Inorg. Chem., 1997, 36, 439-442.

80 S. Nayeri, S. Jamali, A. Jamjah and H. Samouei, Inorg. Chem., 2019, 58, 12122-12131.

81 M. A. Halcrow, Chem. Soc. Rev., 2013, 42, 1784-1795.

82 F. Würthner, T. E. Kaiser and C. R. Saha-Möller, Angew. Chem., Int. Ed., 2011, 50, 3376-3410.

83 A. Mishra, R. K. Behera, P. K. Behera, B. K. Mishra and G. B. Behera, Chem. Rev., 2000, 100, 1973-2011.

84 E. Quartapelle Procopio, M. Mauro, M. Panigati, D. Donghi, P. Mercandelli, A. Sironi, G. D'Alfonso and L. De Cola, J. Am. Chem. Soc., 2010, 132, 14397-14399.

85 J. M. Fernaíndez-Hernaíndez, C. H. Yang, J. I. Beltraín, V. Lemaur, F. Polo, R. Fröhlich, J. Cornil and L. De Cola, J. Am. Chem. Soc., 2011, 133, 10543-10558.

86 A. Valore, E. Cariati, C. Dragonetti, S. Righetto, D. Roberto, R. Ugo, F. De Angelis, S. Fantacci, A. Sgamellotti, A. Macchioni and D. Zuccaccia, Chem. - Eur. J., 2010, 16, 4814-4825. 